EMILY G. MARTIN

\title{
CLAUDE PIRON BEHOLDS HIS BELOVED
}

The Post-Natural Theater is an attempted model of technology's future effect on evolution. Natural landscapes and fertility are encapsulated in dioramas existing between people, as physical translations of human relationships. Existing systems of language are broken down and re-coded. Projected onto the screen of the Theater are histories of the Natural World. 
The Quilt-makers are weaving models of information. Their algorithm visualizes data in sparse matrices, which they can then translate into textures, material tools for future temperature-control, sprawling landscapes, and control of their overflow. They are the last of the Esperanto speakers: a universality as fragile as the practice of tatting lace. They are the Convergence singers, songs of histories and evolutions. Their tongues tut tut. "And what will become of language?" they worry to the Fishermen.

"We are trying to find codes in the landscape; we are practicing alternative methods of translation; we are recording underwater footage of elephants swimming; we are trying to find the answers to aquaphobia and bloat."

"And what will happen when our waters break?"

"Fertility will no longer be necessary; with no function it will ferment, become stinking, perhaps a pleasurable stink, and with no harnessing purpose, it will overflow, spill, multiply exponentially. We will have to encapsulate."

"And where will we put it?"

"We are running out of room." 
Post-Naturalism or Another Theater,

A. Terrain in which individual entities [humans $b$ and $c$, and $d$ ] are no longer as important as their relationships $[b c, c d, b d]$ with one another.

E. The space $[f]$ between.

G. The Diorama: the space of a relationship is encapsulated here, in geometry, in a prism, perhaps, of facing shapes and corresponding planes, or a sphere, its enclosed terrain mappable topographically and cross-sectionally, studied, rendered, and Held, in glass, or latex, or an analogous fiber, or an analogy. This compressed, miniature landscape belongs to its surrounding humans, as much as a physical characteristic can belong to its embodiment.

I. Using one's hands, one can hold this space, support its weight. Hands; and one must, an infinite number must, care for these dioramic ecosystems, landscapes of relationships. Fertilize them with human interaction, speech, thought. Enablers of growth. Lean against the outside if necessary, sleep pressed against the glass and wake up to an outline of condensation.

J. Landscape $[f$ of $b c]$ : Your intimacy is a rainforest enclosed in a plastic tank and it is wet and it overflows and it cannot stop growing. Its fertility is almost disgusting. Its excess. And you touch it; you feel the change in temperature and humidity within this plastic on the skin of your hand placed inside. Its excess is sustained. This moss is thick and this landscape is heavy.

$\mathrm{K}$. The heterotopia is capable of juxtaposing in a single real place several spaces, several sites that are in themselves incompatible. Thus it is that the theater brings onto the rectangle of the stage, one after the other, a whole series of places that are foreign to one another; thus it is that the cinema is a very odd rectangular room, at the end of which, on a two-dimensional screen, one sees the projection of a three-dimensional space. ${ }^{1}$

L. The diorama is no obstacle to flow: each exists in its own dimension, its own plane folded in on other planes. There was a time when relationships had to be carried around; human space has necessitated evolution. There are infinite folded dimensions, thus, we are able to move freely without running into a landscape in the middle of a hallway or a dark movie theater. Yet we can access these dimensions, unfold them intuitively: a diorama can be observed, touched, held, when necessary or desired.

M. Take $b c$ and $c d$. Space [f] of $b c$ does not interfere with Space [o] of $c d$ formally, yet Contents $[o]$ affect Contents [f]. [e.g., Perhaps as the humidity index of Rainforest $o$ rises, the water level of Lake $f$ sinks.] [Perhaps Lake $f$ is the friendship of humans $c$ and $d$.] 
P. Measurements should be taken at fairly regular intervals.

Q. Simulation of flow in cubic cavity 
Diorama: the Projectionist and his mother, the oldest Quilt-maker

Theirs is a garden. Cubic, like Persian rugs stacked on top of each other until the height matches the width because most flat things are really threedimensional. And they choreograph it, starting with the idea of a grid and expanding symmetrically. They have not touched since birth, circling around each other, reeling, moving on two axes. Keep their distance; fill the circles with soil.

A garden is the domestication of the natural world-manicured and controlled, idealized maybe, organic space that is outside, yet private. Native to the soil, yet created by humans; temporal overlap, historical simultaneity, or simulation, one or the other. Very apparently living and dying, growth has agreed to the code of transparency, its hands are now tied; their roots. A plot of land: geometry and edges are to actions and effects as this cube of microcosmic perfection is to encapsulation and at the bottom of everything it's really just dirty and we know the dirt.

If a garden has walls, they protect us from that which we are looking for while we build silences. Sometimes we are reminded of this while inside facing outwards. Their garden has walls made of Plexiglas so the small amount of cross-sectioned soil and miniature roots can be observed, labeled even, which they do at times, while outside facing inwards, lowering their bodies towards the earth. 
Interlude for the Screen

The Projectionist's mother saw the sacrificial horse, once, in a photograph. She held it at arm's length. She became obsessed with the future of cryogenics and documentation, the Southwest's threshold, the obstacle of the plateau. Temperature was an enemy; temperature and time, molecules pressed against her skin. The Southwest is dry, and arid: the question of humidity; the weight of those molecules vary. She rode the horse off the side of a plateau, once, but nothing could freeze in that heat. It was captured on video. 
The Projectionist is curating histories; memory and information embodied in light move toward the screen, bouncing off of it, as opposed to being emitted from a monitor. Sometimes he holds pieces of glass or cellophane in front of the lens-mediating layers-and they do not blur the image, but pixilate it.

The Sculptor is picking apart the cube. He is breaking his fingernails trying to do it, researching. Flattening the cube; building a cube out of clay and then kneading it. Making dough for bread and letting it rise, kneading it, then letting it rise a second time. Braiding the dough, brushing the dough with egg white, forming a mound.

The Quilt-makers are weaving landscapes, patterns of terrain, while the Fishermen by the shore turn code derived from this new landscape into language. And the language is necessary to understand the rise and the fall of land, the intricacies of the viewfinder's allowance.

The Surgeon and his team of Geneticists are exploring a cryogenic recycling of history and possible biological translations of this code. They are discovering what can be born independently of sex, of water, of spillage.

They all discount the question of surveillance of this terrain; they did not invent surveillance. 
Convergence

Perhaps like Quilt-makers, fountains of dictionaries, a few waiting horses, agriculture and scale.

Only the pioneers remain now, the pioneers and the largest animals.

The funeral trains lack human vulnerabilities; obstacles to flow, they fountain.

Burial ground from our teeth above the old landscape, hours of the day and movement of children through them.

There is the great dormant flawlessness of their patterning we spoke of on the telephone with secret terror

And there is architecture being bled of bodily intuitions.

"Hail, solitary ruins!" The terrain of future analysis. It means that the panorama will also play a part.

It is in our historical research. 
By the shore, the elaborate process of projection:

The Projectionist operates a two-reel system: as one film reel nears the end, he begins threading another reel onto the second projector. His own cue marks appear at the upper-right corner of the film. The first cue appears on the film 12 feet [ 8 seconds at 24 frames/second] before he must switch projectors. The second cue appears 1.5 feet [ 1 second at 24 frames/second] before the end of the reel.

82 
He covers the lens of the first projector with the manual changeover shutter and simultaneously opens the shutter of the second projector. This must be timed perfectly: he may not interrupt flow; he is nervous every time.

Some children go swimming in the ocean and the water is cold against their skin and they are entering input. Their mothers watch them from the shore, using their hands to shade their eyes from the sun; they are entering input. A boy finds a beached elephant and he enters input: the stench, the witnessing of the death of a very large animal.

The Projectionist's mother limps towards the body of the elephant; she is pigeon-toed and can't move quickly. She has seen video footage of this particular elephant, once, and knows that the keratin in his ivory can be used to bind fibers. She is the oldest Quilt-maker: she is feeling the sand between her pigeon-toes and remembering what it felt like when it was clay; she enters input. 
Interlude for the Screen

On the Growth of Plants in Closely Glazed Cases-the invention of the terrarium. Nathaniel Ward, a botanist and physicist, grew rare species of ferns, orchids, Japanese and Himalayan palms, cacti and succulents. He poured milk over their roots, encased them in overturned jars, bell-glasses, widemouthed bottles with oiled silk stretched over the openings. The decaying fronds of ferns and the conscious movement of their roots formed a bed of soil made of peat mold, loam, and sand. In the day's heat, moisture rose from the soil inside the case, condensed, dripped back down the sides of the glass: an obvious answer to the question of humidity. Encapsulated, some ferns could survive almost a century without being watered. 
The elk is distracted-undergoing the process of shedding his antlers, he cannot concentrate on the projection. Making contact and leaving a mark, he will sacrifice his keratin to the Great Basin. 
Diorama: The Sculptor and the Surgeon

A swollen forest is encased in their glass sphere, milk of the soil heavy with superstition and virginity, blind to fallow and infrastructure. Moaning boughs of larches and firs leak sap; fertile shades linger in the thickness of the air. Moss and lichen spread gropingly, heaving loam in their wake. The release of their response to fertility: they denature; they question the fermentation of their practice, and leave the rush to rot. Rot the sinew, rot the tendon, rot the spinal cord, rot the synapse, rot the ligament, rot the tissue. 
Convergence

They may often be perceived, blind children whose names have been submerged in water.

How thirsty, the visitor in a herd moaned while he drew enduring patterns of cries, and prayers, for infrastructure:

Emerging forms of modernization, without attempt at opening the body to further study.

Shanghai; another elk exercising an active pressure, watching something offscreen-

Not Braille, not data processing - a burden, still wet, made of the same infinite substance as the meat of bruises-

While children twist by the pool, closely monitoring the suffering of the body and its responses.

The first step in the culture of dissection was told in miniature,

The pure threshold simplified even further as the folding of reasoning so fluid.

Architects, Geneticists, collaborated in the creation of a descriptive anatomy; their materials have become, physically, analogous to invention-

We kept running, and adapted to the general plan in which the real and not so real are produced for the practice of medicine. 
The dinosaurs were distracted; they stood in a row, watching something offscreen. A comet perhaps, or an impending simultaneous excretion. They began to shed their skin, fluorescent at first, peeling off in sheaths, until they were naked, more naked than they thought could ever be possible. They looked at each other slyly; they built a silence that they had never before known. 
Interlude for the Screen

"Nomads of the Desert" was a life-size diorama in hut E of the Desert Environment Area. The scene was in the Saghru, looking north to the Atlas Mountains, in Morocco, near dawn on a summer morning. Often mountainous and rocky rather than sandy, the desert may have seemed barren, but supported grazing by sheep or goats and allowed for limited cultivation near oases fed in spring and summer by melting snows from the surrounding mountains. The Berber nomads in the diorama stayed only a few days as they exploited the resources of the area. Once grazing was exhausted, movement became critical. ${ }^{2}$ 
The Projectionist regulates humidity levels by the shore to keep dust from sticking to the film. He checks the tension of the spools of film at regular intervals so that they don't sag or snap.

The oldest Quilt-maker moves slowly through the Great Basin, her daily rounds, collecting shed antlers, hair, wool, horns, nails, claws, hooves, 90 scales, shells, feathers, beaks, baleen plates. The quills of porcupines. Extraneous roots. Flavors of keratin. These can be boiled down to their essential fibers; the Quilt-makers gossip in Esperanto as they weave the fibers into stretching prisms, intuitively rendering dimensions.

Their collection of materials is divided into categories: organic material that contains DNA (coded fibers), material that was never living (rare earth metals, gemstones, glass), and synthetic material (polyester, Plexiglas, nonglucose-based adhesives). And subdivided based on properties of encasement: swaddling, mummification, permeable membranes, etc. 
A piece of fur is nailed to the wall; it is beautiful. He reaches out to touch it but realizes it is in fact framed behind glass. He wants to touch it. The fur is pressed up against the glass and he wants to touch it more. 
Interlude for the Screen

Pyotr Ilyich Tchaikovsky composed a ballet in two acts, based on E.T.A. Hoffmann's The Nutcracker and the Mouse King in 1892. The ballet was first performed during December of the same year at the Imperial Mariinsky Theatre in Saint Petersburg, choreographed by Marius Petipa and Lev Ivanov. However, it was relatively unpopular until the mid-twentieth century, when William Christensen and George Balanchine staged the performance for the San Francisco Ballet and the New York City Ballet, respectively. In 1977, Mikhail Baryshnikov's Nutcracker was televised by the свS Broadcasting Network, and ran in syndication each following year at Christmastime.

A language of freely combining morphemes, "Esperanto relies entirely on innate reflexes. [...It] differs from all other languages in that you can always trust your natural tendency to generalize patterns." 3 Natural recognition of language forms: choreography becomes its own language. The ballet is a system ascribing meaning to the synchronized movement of bodies. It is a specific ordering of motion, translated from narrative, to classical musical composition, to choreography. Structured motion; the growth of plants in a garden is premeditated by the gardener: the choreography of nature. The domestication of the forest, the domestication of the body. The stage of the theater can be constructed of glass, or latex, or an analogous fiber; it will hold the ballerina. 
He threads the next spool of film through the film gate and onto the takeup reel, rotating the reel clockwise; he determines the speed of this particular history. It is usually twenty-four frames per second, but varies.

The Fishermen ask the Sculptor to repeat a single word aloud until it loses its meaning. They record the sound of his voice and then play it back for him to listen to. 
The Fishermen crowd around a small television monitor by the shore, watching footage of the Mariinsky Ballet performing in Saint Petersburg. A letter arrives to be translated, re-coded, double-sided printing gone awry:

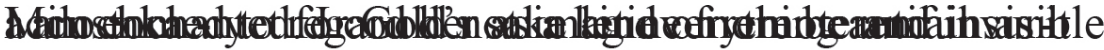

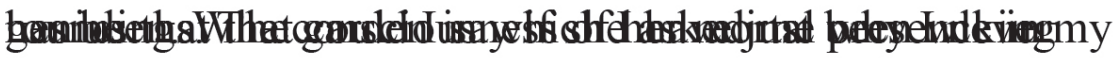

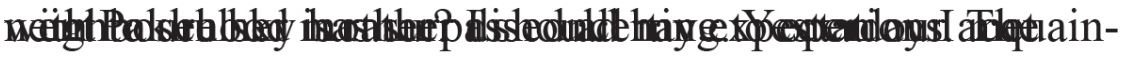

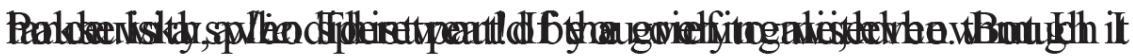

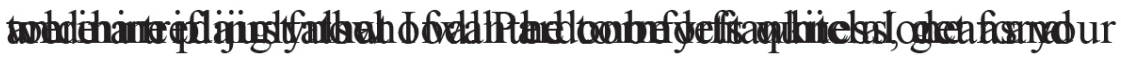
Gendedatyidid.delightful spot!

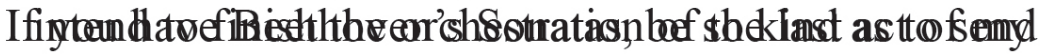

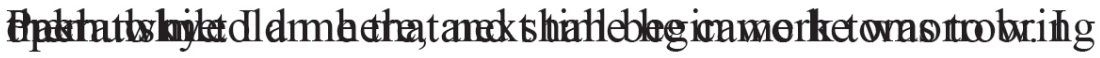

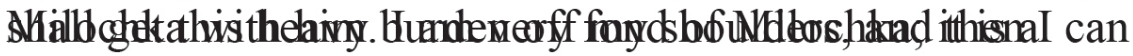

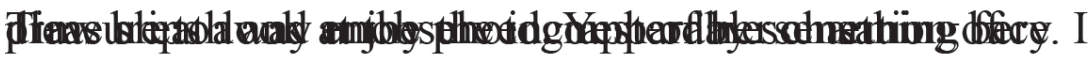

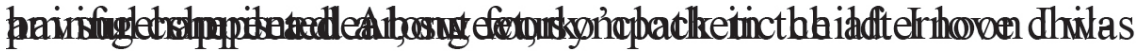

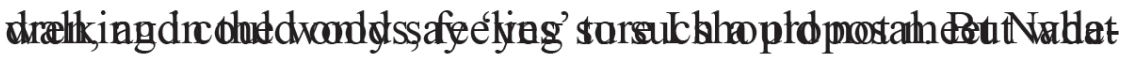

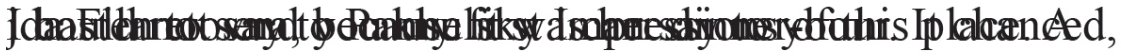

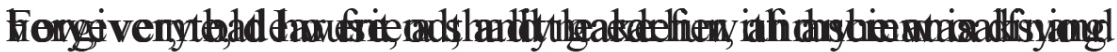

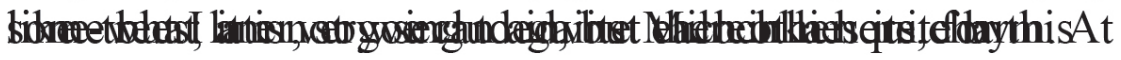

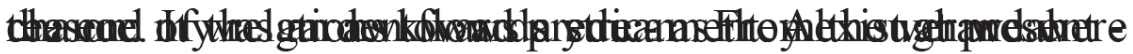

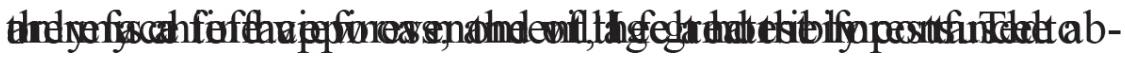

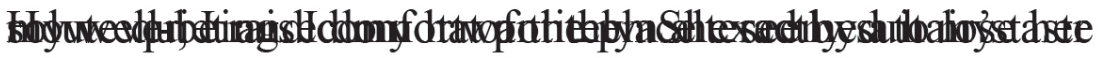

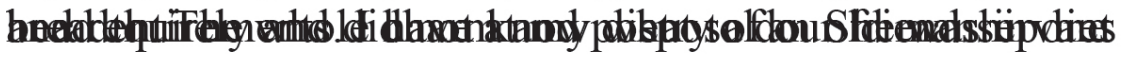

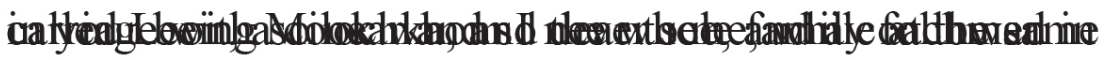

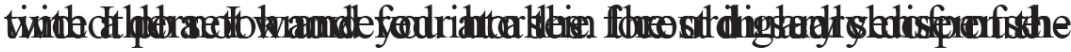

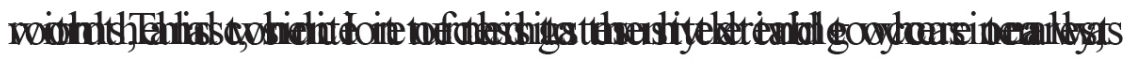

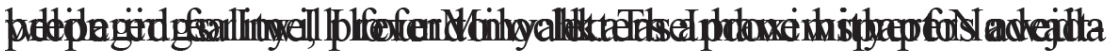

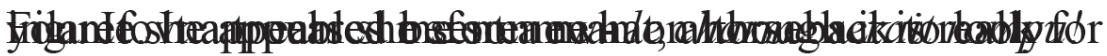

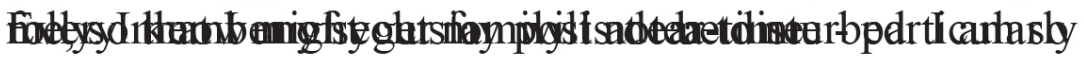


Interlude for the Screen

The first use of Simultaneous Interpretation was during the Nuremburg Trials following the Second World War. Soon after, the United Nations adopted the entirely verbal process as the standard method of communication across national language barriers. In the U.N., the interpreter would sit in a glass, soundproof booth, listening to the orator through headphones while watching the speech through the transparent walls of the booth. The process was fluid, exhausting: the interpreter would convey the message in the output-language as the speaker would continuously speak in the inputlanguage. The interpreter would have to listen to, process, and deliver the message simultaneously, making sure to convey each original semantic element and intention of the speaker. 
Diorama: The youngest Quilt-maker and her even younger lover (the failed correspondence)

A ship wrecks endlessly in their plastic prism. Illegible shattering for years, for they (neither have siblings) will never know each other, really, never know what the other does alone. Algae are born, photosynthesize, and die on the broken pieces of wood; entire life cycles pass before the wreckage finishes sinking. This salt water is infinitely viscous; splintered shards of the ship sink slowly, painfully, into the coral reef at the bottom of their plastic rectangular tank.

The reef multiplies endlessly; living corals layer themselves onto old limestone skeletons, calcifying, cloning themselves, asexual hybrids of plant and animal. The oldest animals in the world. Centuries. The growth pattern of a reef is shaped by the surrounding land, and if that land is rectangular, growth is modeled synthetically. 
The beached elephant repeats a single prayer aloud until it loses its meaning. 
Interlude for the Screen

If the crystal mass and the base rocks have formed a square shape due to the shape of the crystal growing cup, you may want to break off excess crystals from block in order to make the display look more geologically natural. To display your crystal, turn on the LED base by sliding the switch to 'ON' position. Place your clear crystal on the base and watch it appear to change colors. When not using the base, be sure to turn it off by sliding the switch to 'OFF' position. To change the battery, remove the cover with a small screwdriver as shown below.

NOTE: Using your magnifying glass, carefully look at detailed crystalline structure of your finished crystals. 4 
$\mathrm{He}$ is an editor, reviewing, choosing sequences of film from an old reel, cutting them up, splicing them into the new reel.

By the shore, the Sculptor and the Surgeon are watching a television program about children. The children arrange small vessels under the dining room table. The program makes no reference to the children's parents.

The Surgeon is completing experiments depriving infants of human interaction in an attempt to observe the emergence of an autonomous natural language. The Sculptor is compiling research on the largest non-extinct mammals, and the speed at which they move. 
Convergence

Long after worship, the ideal observer's position is at an oblique angle to the screen.

The interfaces become naturalized-driven to post-natural intuition, palpable near mathematical perfection of the forest.

Interfering with sleep, the facial nerves twitch uncontrollably and need to be lengthened; a screen is stretched over the opening of the swimming pool's basin - the same type of cloth used for the winding sheet of a corpse.

The Surgeon probes the body for its secrets, the forest for its domestication of motherhood, the interface for its generation.

He and the Projectionist calculate their angles, compose algorithms and manifestos, their records complete.

100

Long before the advent of the panorama, they were said to use saliva in the preparation of thread for sewing and then to wind it between their toes. 
Interlude for the Screen

Little gap-toothed girl with braids in her hair and a lazy eye ran pigeontoed through the tobacco field. Bare feet beat the cracked clay. The clay that molded the man, kneaded and knotted him into shape; he came from the earth, heavy, primordial clay still fresh with fingerprints.

Ran to the church. The one where her mother was buried, once, beneath the floorboards, with a string of teeth tied round her neck and daffodils in her clenched fist. Pigeon-toed sat at the kitchen table and stared at her bowl of blood and her spider bites. Lazy-eye, Madonna of the soil, counted the teeth strung around her neck. 
Diorama: The oldest Fisherman and the oldest Quilt-maker

Compression of a perfect horizon line, consuming nothing: tundra encased in their prism of semi-opaque, hardened latex. Like the zone of permanent daylight northeast of Saint Petersburg, it is always glowing, illuminated from within; the sun never sets behind the once-transparent walls of the diorama, now screened in translucence. The flatness of their encapsulation, crystallized landscape of permanently frozen soil.

Once, their landscape roared with flow: a forest dripping in wild luxuriance; centuries; now it is perfectly silent, no hushes of growth nor of decay. Lichens were the last life forms they observed, but even those have been buried under the ice fields. The flatness of the ice fields is suffocating; the permanence of their expanse. Something so solid, so close to the ground. And when the sun is rising, or when the sun is setting, which is all the time, the atmosphere is silently and invisibly active in the sub-zero temperature. 
Now unobserved, the children are still arranging small bodies, polished smooth, burying them together. The fur is still pressing up against a piece of 103 glass. 
He switches screens depending on light conditions-stretching the alternate screen at sunrise and at dusk. During the day he uses an aluminized screen that increases the contrast of the image; at night he uses a white screen with thousands of small glass beads woven into the fabric that reflects a more brilliant image in the darkness.

It is said that human conversation comes to a natural pause about every twenty minutes, and the reason for this is that we instinctively eliminate distraction and inspect our environment for possible surrounding predators. Building silences-build vertically the layers surrounding the silence's space and enclose the absence from the front and from behind, before and after. "The existence of space and time in absence" - this is what would have been said.

The Projectionist is looking at the small television monitor by the shore. He sees his own reflection in shapes that are dark, billowing smoke usually. A skin, pressing up against prisoners, women carrying purses, eyes rolling. 
Shanghai was once the most heavily populated space in the world: 7,070.3 people per square mile. Originally a small textile manufacturing and fishing village on the bank of the Huang Pu River, the city became the largest commercial center in China.

In 1842, Britain forced a treaty with the Qing Dynasty after defeating China in the first Opium War. Soon after, France, America, and Japan claimed territory in and around Shanghai. The city quickly became a pioneer of modern technological innovation: the birthplace of Chinese cinema (An Orphan Rescues His Grandfather), and the site of the first electric light bulb in Asia (mid-1930s, Astor House Hotel).

In the first decade of the twenty-first century, Shanghai's Museum of Science and Technology featured approximately sixty-one square miles of floor space, with three floors of exhibition halls. On the first floor: Hall of Widest Spectrum of Life; Earth's Crust Exploration Hall; Light of Wisdom Hall; Children's Techno-Land; Cradle of Designers; IWERKs 4-D Theatre. The second floor: Hall of the Earth Home; Hall of Information Age; The Seeker Corridor; The Robot World; The Spider Exhibition Hall. The third floor: Hall of Exploration Light; Astronavigation World; Hall of People and Health; The Space Theatre. 
The Projectionist's film rips and code flashes repeatedly across the screen.

size:24px; height:29px; height:30px; opacity:1; filter:a lpha (opacity=100); position:absolute; top:0; width: $100 \%$; z-index: 990$\} \# g b x 3\{$ left: 0$\} \# g b x 4\{$ right: 0$\}$.gbtcb \{positio $\mathrm{n}$ :absolute; visibility:hidden\}\#gbz .gbtcb\{right:0\}\#gbg -gbtcb \{left:0\} .gbxx \{display:none

! important\}.gbm\{position: absolute; z-index: 999 ; top:999px; visibility: hidden; text-align: left; border:1px solid \#bebebe; background:\#fff;-moz-box-shadow:-1px $1 \mathrm{px} 1 \mathrm{px}$ \#ccc;-webkit-box-shadow:0 1px 5px \#ccc;boxshadow: $01 \mathrm{px} 5 \mathrm{px}$ \#ccc $\}$.gbrtl .gbm $\{-\operatorname{moz}$-box-shadow:1px $1 \mathrm{px} 1 \mathrm{px} \# \mathrm{CCC}\} \cdot g b t o \cdot g b m, \cdot g b t o$ \#gbs\{top:29px; visibility:visible\}\#gbz .gbm,\#gbz \#gbs $\{$ left: 0$\} \# g b g$.gbm,\#gbg \#gbs $\{$ right: 0$\}$. gboxms $\{$ backgroundcolor:\#ccc; display:block; position:absolute; z-index: 1 ; top:-1px; left:-2px; right:-2px; bottom:-2px; opacity: .4; -moz-border-radius:3px; filter:progid: DXImageTransform . Blur (pixelradius=5); *opacity: 1 ; top: $-2 \mathrm{px}$; * left:-5px; *right: 5px; *bottom:4px;-ms-filter:"progid:DXImageTran sform.Blur (pixelradius=5) "; opacity: $1 \backslash 0 /$; top:-4px $\backslash 0 /$; eft: $-6 \mathrm{px} \backslash 0 /$; right: $5 \mathrm{px} \backslash 0 /$; bottom: $4 \mathrm{px} \backslash 0 /$ \} .gbma \{position :relative; top:-1px; border-style:solid dashed dashed; border-color: transparent; border-topcolor:\#c0c0c0; display:-moz-inline-box; display:inlineblock; font-size:0; height: 0 ; line-height:0; width:0; bord er-width:3px 3px 0;paddingtop: 1px; left: 4px\}\#gbztms1,\#gbi 4m1,\#gbi4s, \#gbi 4t \{zoom: $1\}$.gbtc, .gbmc, .gbmcc\{display:block; list-style:none; ma rgin: 0 ; padding: 0$\}$.gbmc \{background:\#fff; padding:10px 0 ;position:relative; $z-$ index:2; zoom:1\}.gbt \{position:relative; display:-moz-in line-box; display: inline-block; line-height:27px; paddin $g: 0$; vertical-align:top\}.gbt $\{$ *display:inline 
Then overlaps; converges in formation.

5

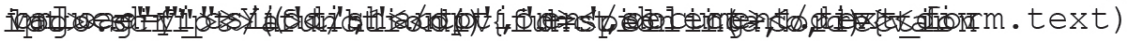
Q.

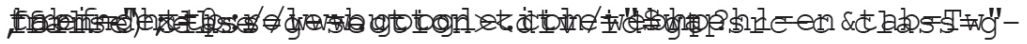

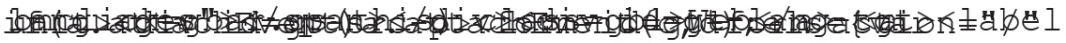

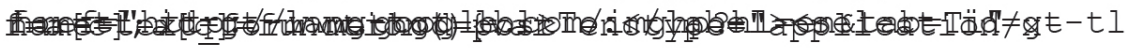

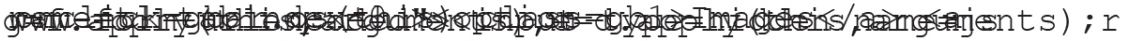

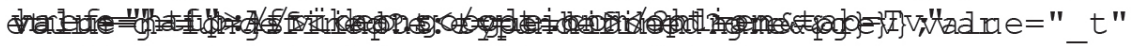

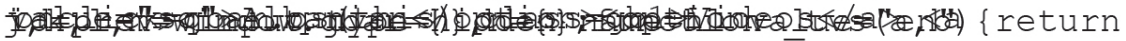

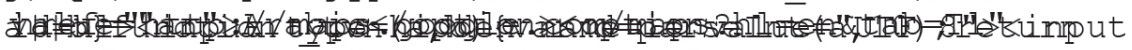
10 4 b

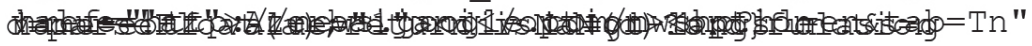

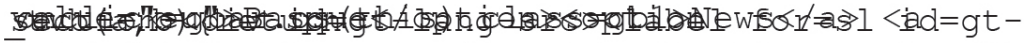

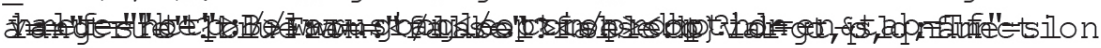

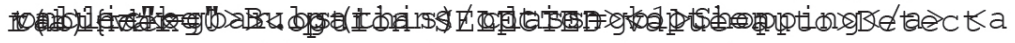

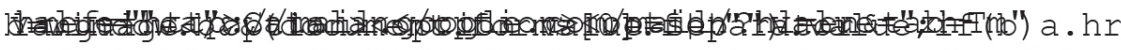

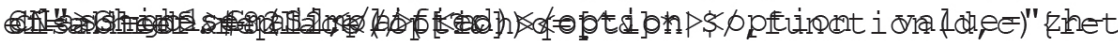

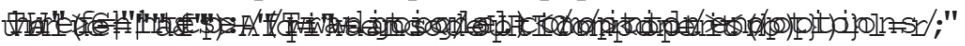

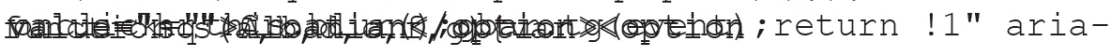
6.

IX

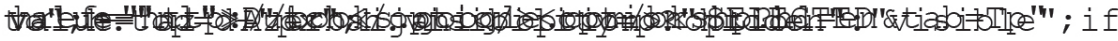

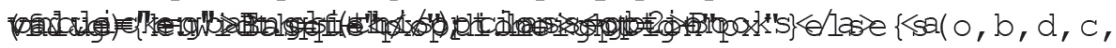

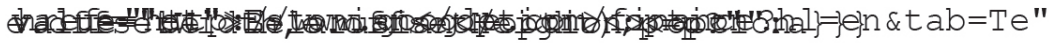

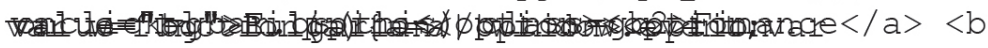
lat A

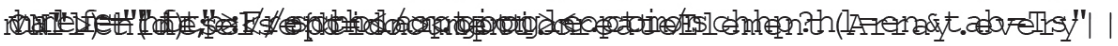

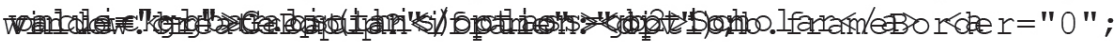

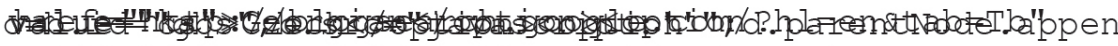

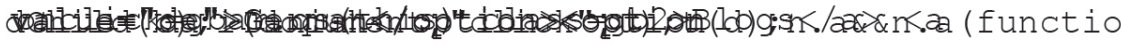

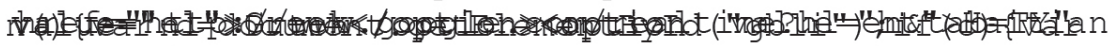

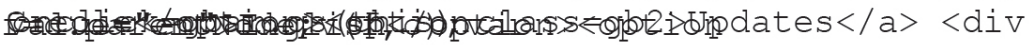
ge日

He has to look away. 
Convergence

Historical denaturing: lectures on anatomy, special study of the fauna of the dead body, mysteries concerning the Dinosaurs, recipes we use.

All the beds were unmade; the root began to dissolve; the age and authenticity of antiquities had become illegible.

The water was a vague terrain - a zone of dissatisfying abstraction-a museum of concealed places where sudden deaths had occurred-

Fertile space susceptible to become pregnant: to create systems where there were none.

A group of Fishermen analyzed the prism's spectrum, simulating magnetism, and began to see patterns: the first piece of code that marked a spot in the landscape,

108

"It is absolutely exact."

They produced cloth, like bags of fat, and ate early lichens beneath an outcropping.

Some figs, eggs on the windowsill (two pairs for adults, two for children), a tiny ghost in an anguished position-

Put the tooth in a glass of water and sometimes an abscess will form.

Two identical children died suddenly in a cold bath, the act of washing, the marks of their bites.

Long after worship, the mummified body was stretched by the widened intervals of the vertebrae; gaps were filled with nail clippings, bits of chewed-off skin.

The fishermen pulled form from extinction, not through images, but through certain practices of language in everyday life; 
The system worked, and they stood there staring at it.

NOTES

1. Michel Foucault, Of Other Spaces, 1967.

2. Thomas D. Nicholson, The Hall of Man in Africa at the American Museum of Natural History, 1973.

3. Claude Piron, The Hidden Perverse Effects of the Current System of International Communication, 1994.

4. Instruction \#10, Smithsonian brand Crystal Growing Kit. 